Analisis Pembebanan Statik pada Rangka Bogie Automatic People MoveSystem (APMS) Menggunakan Standar UIC-615 dengan Finite Element ( Setyo Margo Utomo, Jean Mario Valentin, Beny Halfina, Hendrato)

\title{
ANALISIS PEMBEBANAN STATIK PADA RANGKA BOGIE AUTOMATIC PEOPLE MOVER SYSTEM (APMS) MENGGUNAKAN STANDAR UIC-615 DENGAN FINITE ELEMENT
}

\section{ANALYSIS OF STATIC LOADING ON BOGIE FRAME AUTOMATIC PEOPLE MOVER SYSTEM (APMS) USING UIC-615 STANDARD WITH FINITE ELEMENT}

\author{
Setyo Margo Utomo, Jean Mario Valentino, Beny Halfina, Hendrato \\ Pusat Teknologi Sistem dan Prasarana Transportasi, Badan Pengkajian dan Penerapan \\ Teknologi, Gedung Teknologi II, Lt.3, Kawasan Puspiptek, Serpong, Tangerang Selatan, Banten. \\ Telp: 021-75875943 ext 1122, fax: 021-75875946 \\ setyo.margo@bppt.go.id, jean.mario@bppt.go.id, beny.halfina@bppt.go.id, hendrato@bppt.go.id
}

\begin{abstract}
Abstrak
Bogie merupakan suatu kesatuan konstruksi yang mendukung sarana kereta api monorel saat berjalan diatas track. Rangka bogie merupakan konstruksi untuk mendukung carbody terhadap pembebanan. Tujuan dari analisis ini adalah menentukan dan memastikan batas kekuatan statik rangka bogie secara numerik sebelum prototype rangka bogie melalui proses pengujian statik atau tahap verifikasi desain. Tahapan dalam penelitian ini adalah pengumpulan data dan gambar bogie APMS dari PT.INKA Madiun, kemudian dilakukan identifikasi struktur model 3D CAD bogie, dilanjutkan penentuan boundary conditionsuntuk pembebanan statikdan simulasi pembebanannya.Berdasarkan standar UIC-615 hanya ada dua jenis beban yaitu vertikal dan transversal, dengan nilai maksimumnya adalah $53.234 \mathrm{~N}$ dan $48.619 \mathrm{~N}$.Hasil simulasi pengujian statik untuk beban luar biasa (Static test with exceptional load), terjadi deformasi terbesar $0,5 \mathrm{~mm}$ pada bagian balanced wheel, dan tegangan maksimal sebesar $175,97 \mathrm{MPa}$ yang terletak pada tumpuan anti roll bar, dikarenakan transverse load yang terjadi pada tumpuan anti roll bar tersebut cukup besar. Nilai safety factor yang terjadi pada area anti roll bar tersebut cukup rendah, yaitu 1,39. Hasil simulasi pengujian statik untuk beban kerja (Static test to simulate the main inservice load) didapat nilai safety factor terendah 2,39 dengan nilai tegangan maksimal sebesar 102,26 MPa dan deformasi sebesar 0,339 mm pada saat load case 8 .
\end{abstract}

Kata kunci : Rangka bogie, standar UIC-615, beban statik

\begin{abstract}
Bogie is a unity that supports the construction of railway facilities monorail when running on the track. Bogie frame is a construction to support the carbody against imposition. The purpose of this analysis is to determine and ascertain the limits static strength numerical order before the prototype bogie frame through static testing or verification stage design. Stages in this research is the collection of data and bogie drawing APMS of PT.INKA Madiun, and then to identify the 3D CAD model of the structure of the bogie frame, then conducted to determine the boundary conditions for the imposition of simulated static load.Base on standard UIC-615 there are only two types of load that is vertical and transversal, the maximum value is 53234 and $48619 \mathrm{~N}$. Result of static testing for static tests with exceptional load, the greatest deformation of $0.5 \mathrm{~mm}$ occurs on the balanced wheel, and a maximum stress of 175,97 MPa which lies in the foundation of antiroll bar, due to transverse load occurring on the pedestal of the anti-roll bar is
\end{abstract}


quite large. Safety factor value that occurs in the area of anti-roll bar is quite low, 1,39. The simulation results for the static testing workload (Static test to Simulate the main in-service load) obtained value of the lowest safety factor of 2.39 with a maximum stress value of $102.26 \mathrm{MPa}$ and deformation of $0,339 \mathrm{~mm}$ at the time of load case 8.

Key word: Bogie Frame, UIC-615 Standard, Static Load

Diterima (received) : 15 Juni 2017, Direvisi (reviewed) : 10 Juli 2017, Disetujui

(accepted) : 1 Agustus 2017

\section{LATAR BELAKANG}

Menurut American Society of Civil Engineer (ASCE), definisi APMS adalah sebuah guided transit mode dengan pengoperasian otomatis penuh yang dioperasikan pada jalur yang ekslusif (tidak bercampur dengan moda yang lain) ${ }^{11}$.Pada umumnya APMS ini digunakan di bandara sebagai sarana transportasi penumpang di bandara yang menghubungkan antar terminal.Tipe-tipe dari APMS adalah Cable, Monorel, Automated Guideway Transit (AGT), Maglev dan Personal Rapid Transit (PRT).

APMS produksi PT.INKA pada dasarnya berbasis kereta monorel, yang dikembangkan dengan mengadopsi teknologi dan desain terbaru, namun desain bogie APMS tersebut masih perlu diverifikasi, untuk memastikan keamanan bogie dan kemampuan menahan beban kerja standar maupun beban crush load.

Tujuan dari analisis struktur menggunakan finite element adalah untuk menentukan dan memastikan batas kekuatan rangka bogie, agar memenuhi syarat sebelum melalui proses pengujian, atau yang umum disebut dengan tahap verifikasi desain. Analisis secara statik merepresentasikan perilaku struktur rangka bogie ketika dalam beberapa kondisi, yaitu cruise, side wind, braking dan manuver, dimana terjadi pembebanan maksimal dalam waktu cepat pada struktur rangka bogie dari beban arah vertikal, beban arah lateral maupun beban arah longitudinal, sehingga dapat diketahui area kritis akibat regangan/tegangan maksimum dan defleksi yang terjadi pada struktur bogie. Hasil dari analisis statik ini dapat dipergunakan sebagai referensi peletakan strain gauge ketika dilakukan pengujian statik prototipe bogie APMS.

\section{TINJAUAN PUSTAKA Monorel}

Definisi monorel menurut Peraturan Menteri Perhubungan Republik Indonesia Nomor: PM. 37 Tahun 2014 Tentang Standar Spesifikasi Teknis Sarana Kereta Api Monorel $^{2}$, adalah kereta dengan penggerak sendiri yang berjalan pada 1 (satu) rel dengan menggunakan sumber tenaga listrik dari luar dan/atau dari dalam sebagai penggerak dan dapat dioperasikan dengan/atau tanpa awak sarana perkeretaapian.

Sarana kereta monorel dibagi menjadi 2 jenis, yaitu straddle monorel, merupakan sarana kereta api monorel yang berjalan diatas jalan rel dan suspended monorail, merupakan sarana kereta api monorel yang berjalan menggantung pada jalan rel. Sarana kereta api monorel terdiri dari badan kereta dan bogie. Bogie merupakan suatu kesatuan konstruksi yang mendukung sarana kereta api monorel saat berjalan diatas rel lengkung atau lurus untuk kestabilan dan kenyamanan. Rangka bogie merupakan konstruksi yang dirancang untuk mendukung badan terhadap pembebanan.

Rangka harus memenuhi persyaratan yaitu memiliki kekuatan serta kekakuan tinggi terhadap pembebanan vertikal, lateral dan longitudinal tanpa terjadi deformasi tetap dan tidak terjadi cacat (retak) pada titik kritis akibat pembebanan.

\section{Analisis Statik}

Hal yang terpenting dalam tahapan disain suatu komponen mekanik adalah pengetahuan tentang beban yang bekerja pada komponen mekanik tersebut. Syarat utama untuk melakukan analisis gaya adalah benda pada bidang atau ruang yang akan dianalisis harus dalam keadaan setimbang statik, sehingga resultan gaya dan momen yang bekerja pada benda tegar itu adalah nol [3]. Persamaan umum untuk kesetimbangan statik benda tegar dapat dinyatakan dengan: 
Analisis Pembebanan Statik pada Rangka Bogie Automatic People MoveSystem (APMS) Menggunakan Standar UIC-615 dengan Finite Element ( Setyo Margo Utomo, Jean Mario Valentin, Beny Halfina, Hendrato)

$$
\begin{aligned}
& \sum F=0 \\
& \sum M=0
\end{aligned}
$$

Jika $\sum F=0$ diuraikan dalam arah sumbu $x$, y dan z diperoleh:

$$
\begin{aligned}
& \sum F x=0 \\
& \sum F y=0 \\
& \sum F z=0
\end{aligned}
$$

Fx adalah komponen gaya dalam arah sumbu $x$, Fy adalah komponen gaya dalam arah sumbu y dan $\mathrm{Fz}$ adalah komponen gaya dalam arah sumbu $z$.

\section{Finite Element Analysis}

Konsep dasar finite element analysis adalah mendiskretisasi atau membagi suatu struktur menjadi bagian-bagian yang lebih kecil yang jumlahnya berhingga, kemudian melakukan analisis gabungan terhadap elemen-elemen kecil tersebut. Nilai pendekatan numerik diperoleh melalui bantuan komputer, sehingga finite element analysis bersifat computer oriented ${ }^{4)}$.

Tahap-tahap dasar dalam finite element analysis adalah pre-processing, yaitu melakukan diskretisasi model menjadi elemen-elemen hingga, dalam bentuk nodalnodal dan elemen-elemen.Selanjutnya menggabungkan elemen-elemen lokal menjadi solusi global, dan membentuk matriks kekakuan global sekaligus mengaplikasikan kondisi batas, kondisi awal, dan beban-beban yang terjadi.

Tahap kedua adalah processing atau solving, dimana komputer menyelesaikan sejumlah perhitungan aljabar linier atau non linier sesuai kondisi yang diterapkan pada tahap pre-processing. Kemudian tahap terakhir adalah post processing, yaitu mengorganisasi dan mengintepretasi data hasil perhitungan yang berupa gambar, kurva atau animasi.

\section{METODOLOGI}

Tahap pertama untuk melakukan analisa beban statik pada rangka bogie, mempersiapkan model solid 3D CAD bogie beserta assembly danmelakukan validasi terhadap model struktur bogie.Kualitas sebuah model dianggap valid jika tidak ada tumpang tindih komponen (zero interference) dan sambungan-sambungannya terdefinisi secara sempurna (fully defined).
Apabila validasi kualitas model belum terpenuhi, maka dilakukan editing terlebih dahulu terhadap model CAD agar supaya tidak terjadi interference dan assembly terdefinisi dengan sempurna. Model CAD yang digunakan untuk analisis hanya berupa struktur rangka utama, tanpa dilengkapi sistem roda, propulsi dan suspensi ${ }^{5}$ ).

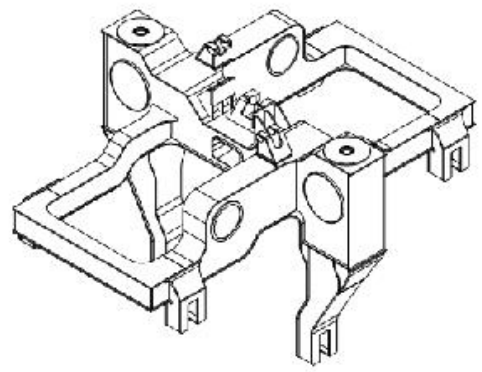

Gambar 1.

Model Rangka Utama Bogie yang Sudah Disederhanakan

Selain melakukan validasi model, dilakukan pula penyederhanaan model CAD (Gambar 1) agar model kompatibel untuk perhitungan elemen hingga dan agar supaya proses komputasi tidak terlalu berat. Efek dari penyederhanaan model adalah terjadi perbedaan hasil perhitungan bila dibandingkan dengan model aslinya, karena itu sebelum penyederhanaan model dilakukan, perlu dipastikan bahwa tidak ada area kritis pada model. Apabila dijumpai adanya area kritis, maka model perlu dianalisa ulang tanpa dilakukan penyederhanaan. Penyederhanaan yang dilakukan adalah penghilangan lubanglubang baut untuk menghilangan konsentrasi tegangan ketika dilakukan mesh.

Tahap selanjutnya adalah menentukan definisi kondisi batas (boundary condition) pada model CAD (Gambar 2), yaitu jenis tumpuan yang digunakan dan menentukan degree of freedom berupa translasi atau rotasi pada arah sumbu simetri sesuai dengan kondisi yang sebenarnya. Bogieditumpu pada kedua roda utama yaitu roda yang berfungsi sebagai penahan beban arah vertikal (fix sumbu $z$ ) dan penggerak kereta arah longitudinal (fix sumbu $\mathrm{x}$ ), dan enam roda samping yang berfungsi sebagai tumpuan arah lateral (fix sumbu y). 


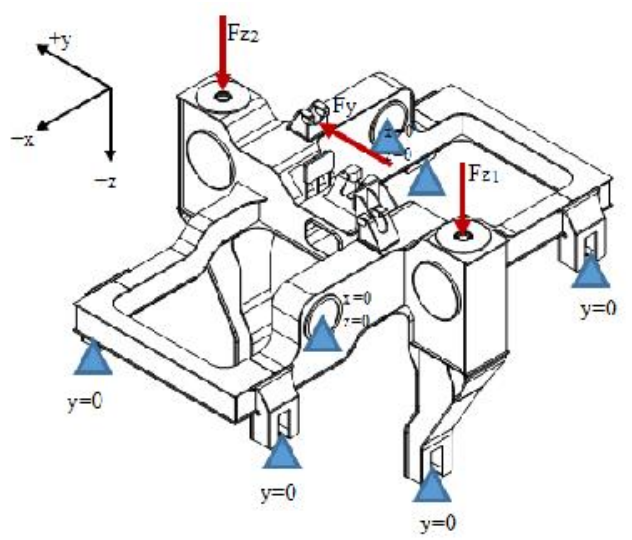

Gambar 2.

Beban Pada Rangka Bogie

Metode perhitungan pembebanan statik berdasarkan standar internasional UIC 615-4 tentang Motive Power Unit - Bogies and Running Gear - Bogie Frame Structure Strength Test. Standar ini menjelaskan tentang technical approval untuk motor bogie, yaitu performa rig test untuk verifikasi kemampuan bogie untuk menahan beban kerja $^{6) .}$ Standar ini dibedakan menjadi:

1) Static test with exceptional load (Pengujian statik untuk beban yg luar biasa). Pengujian ini untuk melakukan verifikasi bahwa tidak ada resiko deformasi permanen pada bogie ketika dikenakan beban kerja maksimum.

2) Static test to simulate the main in-service load (Pengujian statik untuk beban kerja). Pengujian ini untuk melakukan verifikasi bahwa tidak ada resiko crack akibat beban kerja, seperti beban vertikal dan beban lateral; dan efek track twist.

3) Static test to simulate particular in-service load (Pengujian statik untuk beban tertentu). Simulasi ini untuk memastikan bahwa tidak ada resiko lokal crack akibat stress yang berulang-ulang pada komponen bogie seperti motor, rem, suspensi, anti-roll bar, termasuk dari beban akibat melewati radius track yang kecil.

Berdasarkan data dari PT.INKA, material yang digunakan untuk seluruh rangka bogie adalah SM490A (JIS G3106)7). Baja SM 490 A adalah baja rol yang bisa digunakan dalam struktur-struktur engineering, khususnya pada struktur yang dilas. SM 490A memiliki kesetaraan dalam klasifikasi JIS G3106 standard dan ASTM A 572. Ketebalan pelat SM 490A dari pabrik bervariasi mulai dari $6 \mathrm{~mm}$ sampai dengan 300 mmdengan sifat mekanis material sebagai berikut :
Modulus young
Elongation
$: 210 \mathrm{GPa}$
Yield strength
$: 17 \%$
Ultimate tensile strength: $490 \mathrm{MPa}$
Poisson Ratio
Density
$: 0,3$
$: 7800 \mathrm{~kg} / \mathrm{m}^{3}$

\section{HASIL DAN PEMBAHASAN}

Simulasi statik untuk bogie APMS ini mengikuti metode pengujian sesuai UIC 6154, namun dilakukan secara numerik menggunakan finite element analysis. Berikut adalah notasi dan definisi beban pada UIC 615:

$$
\begin{aligned}
& \mathrm{n}_{\mathrm{b}}=\text { number of bogies } \\
& \mathrm{n}_{\mathrm{e}}=\text { number of wheelset per bogie } \\
& \mathrm{m}^{+}(\mathrm{kg}) \quad=\text { bogie weight } \\
& \mathrm{mv}(\mathrm{kg}) \quad=\text { empty weight of vehicle }
\end{aligned}
$$

Pengujian ini ditujukan untuk passanger carrying vehicles, yang dihitung berdasarkan UIC 566.

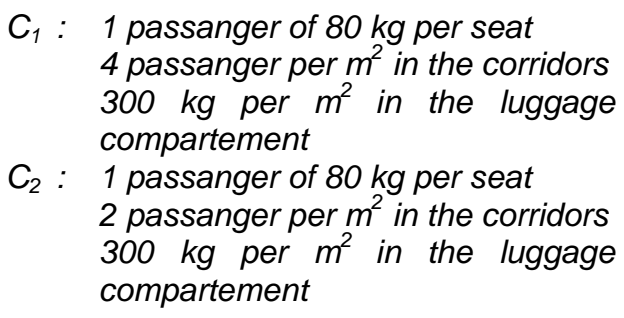

\section{Static test with exceptional load}

Definisi beban menurut UIC 615-4 untuk Static Tes with Exceptional Load(Pengujian statik untuk beban yg luar biasa):

- Vertical test load per bogie:

$$
\begin{aligned}
& F_{z 1 \max }(N)=F_{z 2 \max }(V) \\
& -\frac{L, 4 g}{2 n_{b}}\left(m_{V}+C_{1}-n_{b} m^{+}\right)
\end{aligned}
$$

- Transverse test load per bogie:

$$
F_{y \max }=2\left[10^{4}, \frac{\left(m_{v}-c_{1}\right) g}{3 n_{s} n_{b}}\right]
$$


Analisis Pembebanan Statik pada Rangka Bogie Automatic People MoveSystem (APMS) Menggunakan Standar UIC-615 dengan Finite Element ( Setyo Margo Utomo, Jean Mario Valentin, Beny Halfina, Hendrato)

\section{Tabel 1}

Perhitungan Static test with exceptional load

\begin{tabular}{ccr}
\hline Notasi & Definisi & \multicolumn{1}{c}{ Value } \\
\hline $\mathbf{n b}$ & number of bogies & 4 \\
$\mathbf{n e}$ & num.of wheelset per bogie & 2 \\
$\mathbf{m +}$ & bogie weight $(\mathrm{kg})$ & 1000 \\
$\mathbf{m v}$ & empty weight vehicle $(\mathrm{kg})$ & 12000 \\
& $80 \mathrm{~kg}$ per seat & 3200 \\
$\mathbf{c 1}$ & 4 pax per m2 & 10224 \\
& $300 \mathrm{~kg}$ per m2 & 9585 \\
& total C1 & 23009 \\
& $80 \mathrm{~kg}$ per seat & 3200 \\
$\mathbf{c 2}$ & 2 pax per m2 & 5112 \\
& 300 kg per m2 & 9585 \\
& Total C2 & 17897 \\
Fz1 & Vertical load 1 $(\mathrm{N})$ & 53234.7 \\
Fz2 & Vertical load 2 $(\mathrm{N})$ & 53234.7 \\
Fy max & Transverse load $(\mathrm{N})$ & 48619.86 \\
\hline
\end{tabular}

Sumber Data : Hasil Olahan Data Penelitian

Dari tabel 1 diatas, didapatkan nilai $F_{z 1}, F_{z 2}$ dan $F_{y}$ max untuk digunakan sebagai nilai beban yang terjadi pada bogie. Beban $F_{z 1}$ dan $F_{\mathrm{z} 2}$ (vertical load) terletak pada air suspension plate dan $\mathrm{F}_{\mathrm{y}}$ max (transverse load) terletak pada anti roll bar. Berikut adalah hasil simulasi menggunakan ANSYS:

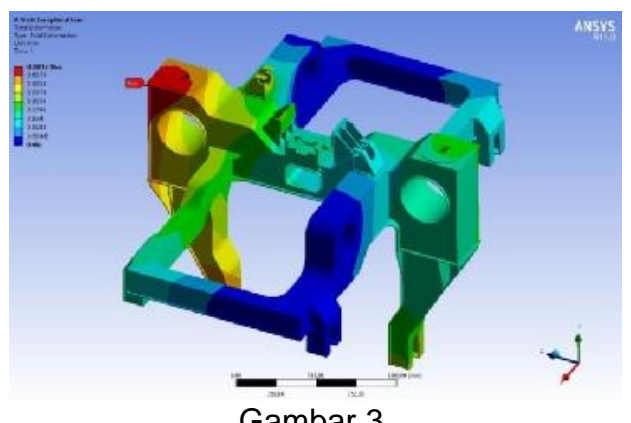

Hasil Solusi Deformasi with Exceptional Load.

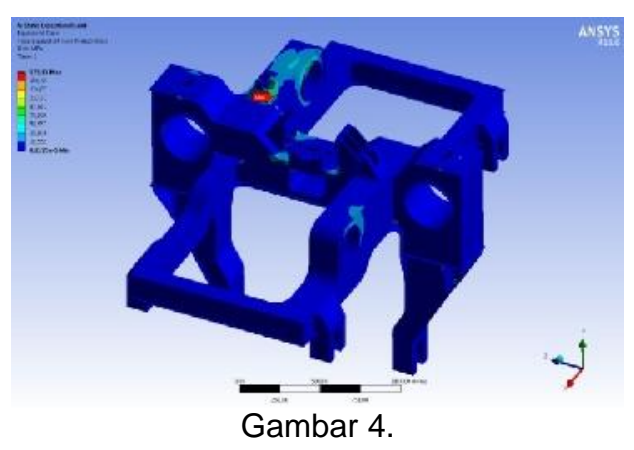

Hasil Solusi von Mises Stress with Exceptional Load

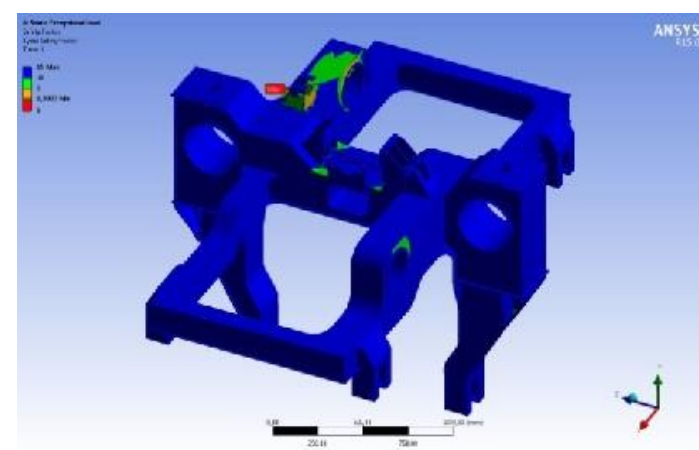

Gambar 5.

Hasil Solusi Safety Factor with Exceptional Load

Gambar 3 adalah deformasi sebesar 0,5 mm pada static test with exceptional load, yaitu ketika dikenakan beban kerja maksimum. Deformasi yang terjadi pada bagian balanced wheel. Dari pembebanan diatas, didapatkan hasil simulasivon misses stress maksimal sebesar $175,97 \mathrm{MPa}$ yang terletak pada tumpuan anti roll bar seperti pada gambar 4, hal ini dikarenakan karena transverse load yang terjadi pada tumpuan anti roll bar tersebut cukup besar. Dikarenakan stress yang terjadi cukup tinggi, maka nilai safety factor yang terjadi pada area anti roll bar tersebut cukup rendah, yaitu 1,39 (gambar 5).

\section{Static test to simulate the main in-service load}

Definisi beban kerja menurut UIC 615-4 untuk Static testto simulate the main inservice load(Pengujian statik untuk beban kerja):

- Vertical test load per bogie:

$$
F_{z}(N)=\frac{g}{2 n_{b j}}\left(m_{v}+1,2 C_{2}-n_{\varepsilon} m^{+}\right)
$$

- Transverse test load per bogie:

$$
F_{y}(N)=0.5\left(F_{z}+0,5 m^{+} g\right)
$$

Pada pengujian statik ini, terdapat 9 variasi pengujian (load case). Variasi dinamis gaya vertikal karena gerakan vertikal (bouncing) pada badan kereta, direpresentasikan oleh persentase $\beta$ pada gaya vertikal $\beta F z$. Sedangkan variasi dinamis gaya vertikal karena gerakan rolling pada badan kereta, direpresentasikan oleh persentase $\alpha$ pada gaya vertikal $\alpha F z$. Untuk pengoperasian pada kondisi normal di European Railways, didapatkan: 


$$
\alpha=0,1 \quad \beta=0,2
$$

Berikut adalah tabel konfigurasi load case sesuai UIC 615:

Tabel 2.

Konfigurasi Load CaseMain in-Sevice Load

\begin{tabular}{|c|c|c|c|}
\hline \multirow[b]{2}{*}{$\begin{array}{l}\text { Load } \\
\text { Case }\end{array}$} & \multicolumn{2}{|c|}{ Vertical force per solebar } & \multirow{2}{*}{$\begin{array}{c}\text { Transverse } \\
\text { force } \\
\text { exerted on } \\
\text { bogie }\end{array}$} \\
\hline & $F_{z 1}$ & $\mathrm{~F}_{\mathrm{z} 2}$ & \\
\hline 0 & $\begin{array}{c}\text { Installation of tr } \\
\text { motors }\end{array}$ & ction & 0 \\
\hline 1 & $F_{z}$ & $\mathrm{~F}_{z}$ & 0 \\
\hline 2 & $(1+-\beta) F_{z}$ & - $\beta) F_{z}$ & 0 \\
\hline 3 & $(1+-\beta) F_{z}$ & - $\beta) F_{z}$ & $+F_{y}$ \\
\hline 4 & $(1++\beta) F_{z}$ & $+\beta) F_{z}$ & 0 \\
\hline 5 & $+\beta) F_{z}(1-$ & $+\beta) F_{z}$ & $+\mathrm{F}_{\mathrm{y}}$ \\
\hline 6 & $(1-\quad-\beta) F_{z} \quad(1+$ & $-\beta) F_{z}$ & 0 \\
\hline 7 & $(1--\beta) F_{z} \quad(1+$ & - $\beta) F_{z}$ & $-F_{y}$ \\
\hline 8 & $(1-+\beta) F_{z} \quad(1+$ & $+\beta) F_{z}$ & 0 \\
\hline 9 & $(1-+\beta) F_{z}(1+$ & $+\beta) F_{z}$ & $-F_{y}$ \\
\hline
\end{tabular}
sesuai UIC 615

Maka didapatkan hasil perhitungan seperti pada tabel 3 dibawah berikut ini.

Tabel 3.

Hasil Perhitungan Static Test to Simulate Main in-Service Load

\begin{tabular}{crrr}
\hline Load & \multicolumn{2}{c}{ Vertical Force (N) } & \multicolumn{1}{c}{$\begin{array}{c}\text { Transverse } \\
\text { Force (N) }\end{array}$} \\
\cline { 2 - 3 } & \multicolumn{1}{c}{ Fz1 } & \multicolumn{1}{c}{ Fz2 } & \\
\hline 1 & 36145,4355 & 36145,4355 & 0 \\
2 & 32530,892 & 25301,8049 & 0 \\
3 & 32530,892 & 25301,8049 & 20525,21775 \\
4 & 46989,0662 & 39759,9791 & 0 \\
5 & 46989,0662 & 39759,9791 & 20525,21775 \\
6 & 25301,8049 & 32530,892 & 0 \\
7 & 25301,8049 & 32530,892 & $-20525,2178$ \\
8 & 39759,9791 & 46989,0662 & 0 \\
9 & 39759,9791 & 46989,0662 & $-20525,2178$ \\
\hline
\end{tabular}

Beban $F_{z 1}$ dan $F_{z 2}$ (vertical load) terletak pada air suspension plate dan $\mathrm{F}_{\mathrm{y}}$ max (transverse load) terletak pada anti roll bar.Berikut adalah hasil simulasi menggunakan ANSYS:

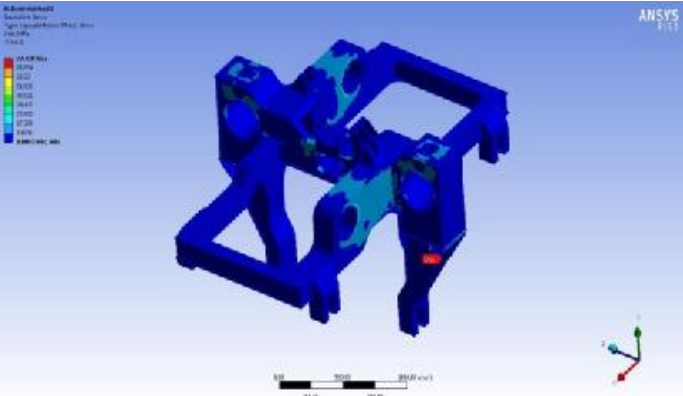

Gambar 6.

Hasil Solusi von Mises Stress with Main inservice Load Case 1

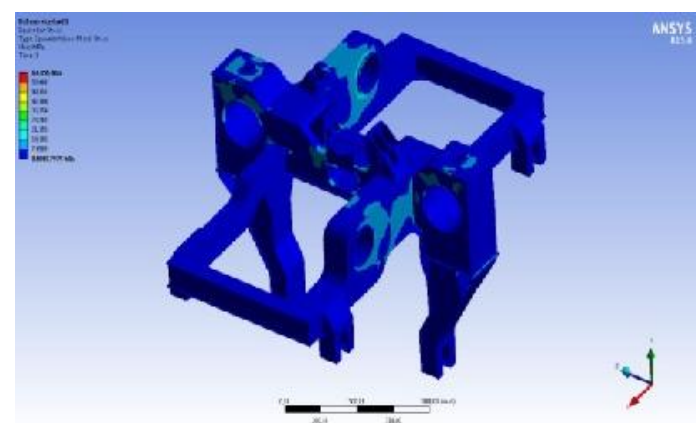

Gambar 7.

Hasil Solusi von Mises Stress with Main inservice Load Case 2

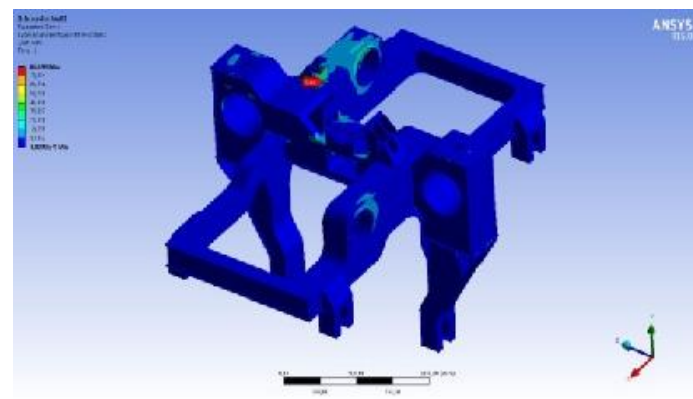

Gambar 8.

Hasil Solusi von Mises Stress with Main inservice Load Case 3

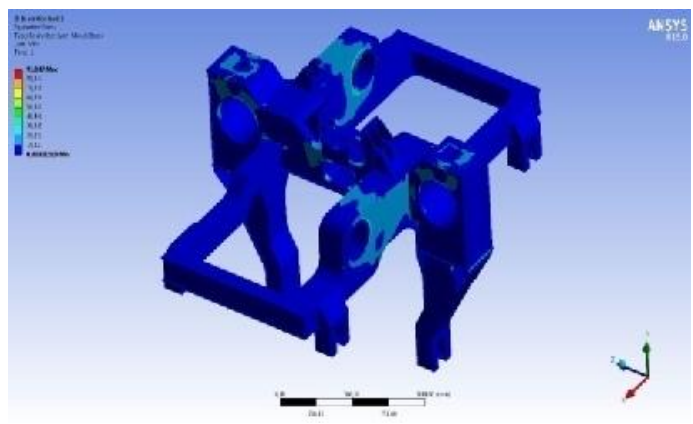

Gambar 9.

Hasil Solusi von Mises Stress with Main inservice Load Case 4 
Analisis Pembebanan Statik pada Rangka Bogie Automatic People MoveSystem (APMS) Menggunakan Standar UIC-615 dengan Finite Element ( Setyo Margo Utomo, Jean Mario Valentin, Beny Halfina, Hendrato)

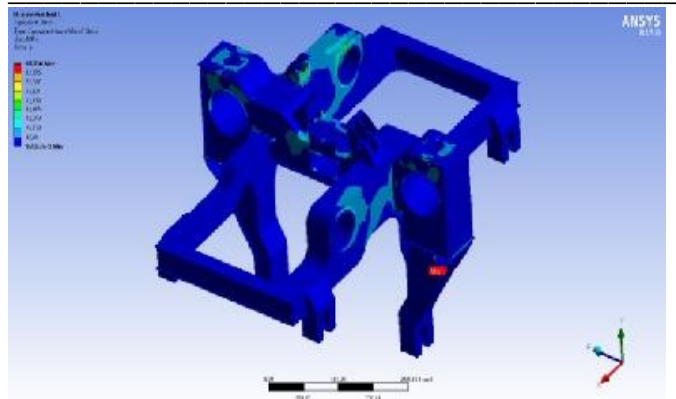

Gambar 10.

Hasil Solusi von Mises Stress with Main inservice Load Case 5

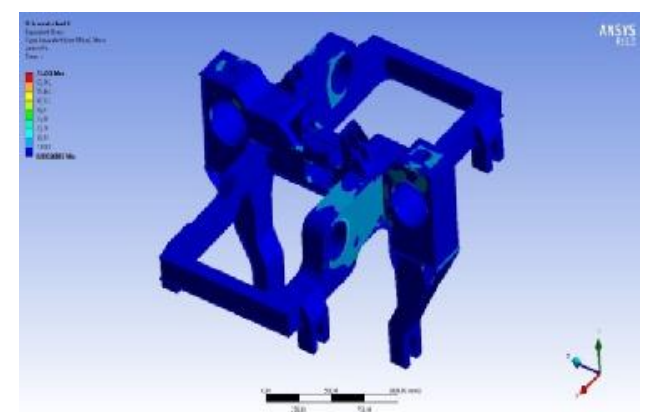

Gambar 11.

Hasil Solusi von Mises Stress with Main inservice Load Case 6

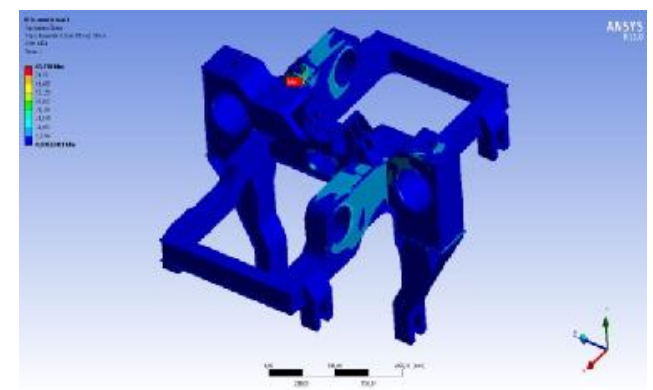

Gambar 12.

Hasil Solusi von Mises Stress with Main inservice Load Case 7

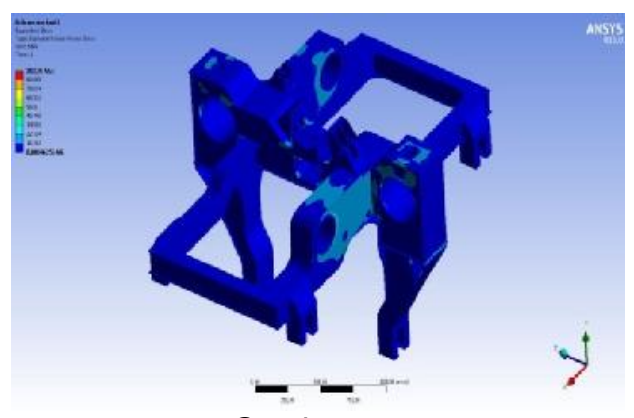

Gambar 13.

Hasil Solusi von Mises Stress with Main inservice Load Case 8

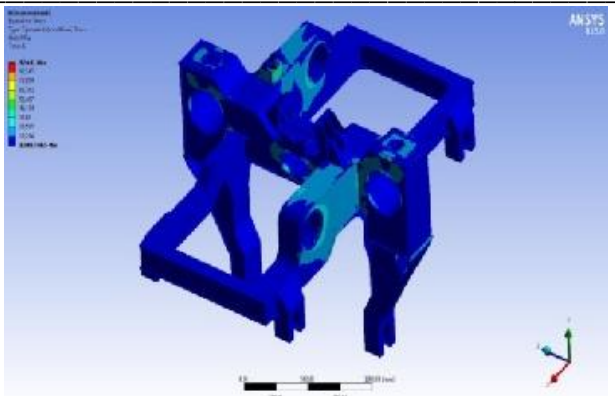

Gambar 14

Hasil Solusi von Mises Stress with Main inservice Load Case 9

Tabel berikut adalah rangkuman 9 load case, yaitu deformasi, von mises stress dan safety factor:

Tabel 4.

Rangkuman Hasil Simulasi Main in-service

$$
\text { Load. }
$$

\begin{tabular}{cccc}
\hline $\begin{array}{c}\text { Load Deformation } \\
\text { Case }\end{array}$ & $\begin{array}{c}\text { von Mises } \\
\text { (mm) }\end{array}$ & $\begin{array}{c}\text { Stress } \\
\text { (MPa) }\end{array}$ & $\begin{array}{c}\text { Safety } \\
\text { Factor }\end{array}$ \\
\hline 1 & 0,256 & 77,438 & 3,16 \\
2 & 0,237 & 63,456 & 3,86 \\
3 & 0,283 & 88,193 & 2,77 \\
4 & 0,339 & 91,047 & 2,69 \\
5 & 0,37 & 93,236 & 2,62 \\
6 & 0,236 & 71,281 & 3,43 \\
7 & 0,262 & 85,738 & 2,85 \\
8 & 0,338 & 102,26 & 2,39 \\
9 & 0,364 & 92,641 & 2,64 \\
\hline
\end{tabular}

Dari tabel 4 diatas, bisa dicari nilai tegangan rata-rata, amplitudo tegangan, range tegangan dan rasio tegangan menggunakan formula dibawah ini:

$$
\begin{aligned}
& \text { Stress range }: \Delta \sigma=\sigma_{\max }-\sigma_{\min }(10) \\
& \text { Stress amplitude: } \sigma_{a}=\frac{\sigma_{\max }-\sigma_{\min }}{z}(11) \\
& \text { Mean stress: } \sigma_{a}=\frac{\sigma_{\max }+\sigma_{\min }}{2} \\
& \text { Stress ratio: } R=\frac{\sigma_{\min }}{\sigma_{\max }}
\end{aligned}
$$

Hasil dari perhitungan diatas ditampilkan seperti pada tabel 5 berikut:

Tabel 5.

Hasil Perhitungan Tegangan rata-rata

\begin{tabular}{cccc}
\hline $\begin{array}{c}\text { Stress } \\
\text { Range } \Delta \sigma \\
(\mathrm{MPa})\end{array}$ & $\begin{array}{c}\text { Stress } \\
\text { Amplitude } \\
(\mathrm{MPa})\end{array}$ & $\begin{array}{c}\text { Mean } \\
\text { Stress } \\
(\mathrm{MPa})\end{array}$ & $\begin{array}{c}\text { Stress } \\
\text { Ratio R } \\
(\mathrm{MPa})\end{array}$ \\
\hline 38,804 & 19,402 & 82,858 & 0,620 \\
\hline$a x^{2}+b x+c=0$ & &
\end{tabular}




\section{SIMPULAN}

Berdasarkan analisis pembebanan pada standar UIC 615, terdapat dua beban utama yang diterima rangka bogie, yaitu beban vertikal dan transversal, dengan masingmasing nilai maksimumnya sebesar 53.234 $\mathrm{N}$ dan $48.619 \mathrm{~N}$.

Hasil simulasi pengujian statik untuk beban yang luar biasa (Static test with exceptional load), terjadi deformasi terbesar $0,5 \mathrm{~mm}$ yang terjadi pada bagian balanced wheel, dan tegangan maksimum sebesar 175,97 $\mathrm{MPa}$ yang terletak pada tumpuan anti roll bar, dikarenakan transverse load yang terjadi pada tumpuan anti roll bar tersebut cukup besar. Nilai safety factor yang terjadi pada area anti roll bar tersebut cukup rendah, yaitu sebesar 1,39.

Hasil simulasi pengujian statik untuk beban kerja (Static test to simulate the main inservice load) didapat nilai safety factor terendah 2,39 dengan nilai tegangan maksimum sebesar 102,26 $\mathrm{MPa}$ dan deformasi sebesar $0,339 \mathrm{~mm}$ pada saat load case 8.

Secara umum rangka bogie APMS dinyatakan aman menggunakan perhitungan finite element, karena stress yang terjadi masih dibawah nilai yield material, namun masih perlu divalidasi lebih lanjut dengan menggunakan pengujian statik pada prototipe yang sesungguhnya.

\section{DAFTAR PUSTAKA}

1. Automated People Mover StandardsPart 1, 2006, American Society of Civil Engineers (ASCE).

2. Peraturan Menteri Perhubungan Republik Indonesia Nomor: PM. 37 Tahun 2014 Tentang Standar Spesifikasi Teknis Sarana Kereta Api Monorel.

3. Budynas, Richard G.,Shigley's Mechanical Engineering Design (9th ed.). McGraw Hill: USA, 2011.

4. Moaveni, Saeed.,Finite Element Analysis : Theory and Application with ANSYS. Pearson Prentice Hall: USA, 2008.

5. Dokumen Resmi Gambar Teknik dan Spesifikasi Teknis Automatic People Mover PT.INKA.

6. UIC Code 615, Motive Power UnitsBogie and Running Gear-Bogie Frame Structure Strength Test, $2^{\text {nd }}$ Edition, Februari 2003.

7. Krauss, George.,Steels: Processing, Structure, and Performance. ASM International: USA, 2005.

8. ANSYS Workbench User's Guide Release 15, 2013.

9. Liliana, Rusu-Casandra, et.al, Stresses in a Bogie Frame of a Rail Carriage.Procedia Engineering, Volume 100, 2015, pp 482-487.

10. Kassner, M., Fatigue strength analysis of a welded railway vehicle structure by different methods. International Journal of Fatigue, Volume 34, Issue 1, 2012 